\title{
OBITUARIO
}

\section{JORGE EDUARDO WRIGHT}

(1922-2005)

El 4 de enero de 2005, el Dr. Jorge Eduardo Wright nos dejó físicamente. Perdurarán en el recuerdo su conocimiento científico, su invalorable memoria y sobre todo, ese don de padre, consejero y amigo que muchos hemos disfrutado.

El día que conocí al Dr. Jorge Wright, llegaba a la Capital desde Corrientes. Decidí almorzar antes de subir al $4^{\circ}$ piso del Pabellón II en la Ciudad Universitaria (UBA). Luego de la presentación de rigor, su primera frase fue: Te esperaba más temprano.

$\mathrm{Su}$ exigencia constante, aunque nunca excesiva, acompañada de mucha seriedad, muy buena predisposición y contagioso entusiasmo,

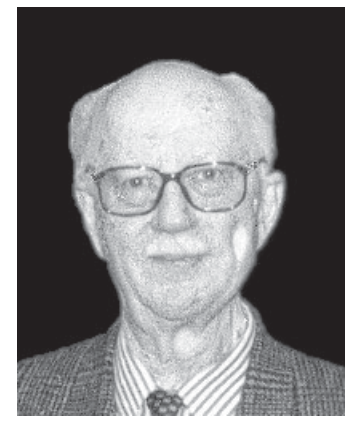
eran su "marca registrada" para el trabajo. Enseñaba con el ejemplo y nunca dejaba de ser curioso ni perdía el interés de seguir aprendiendo, privilegio de los que más saben.

El único descanso que se permitía en su día de trabajo, era durante el almuerzo, pero ni siquiera en esos momentos, dejaba de enseñar con sus valiosas y entretenidas anécdotas, o de hacer esas preguntas directas que también lo hicieron memorable en el ámbito académico. A continuación era conocida su frase: Back to work!

Indudablemente fue y será un referente en el estudio de los hongos, gracias al impulso que le dio a la micología, reflejado en su profusa labor de investigación y docencia.

Mientras todavía era estudiante universitario, fue profesor de Biología en el prestigioso Colegio Carlos Pellegrini y profesor de inglés en el Liceo Naval Militar. Fue Auxiliar en el Laboratorio de Fitopatología del Instituto de Sanidad Vegetal, del Ministerio de Agricultura y Ganadería, donde alcanzó el cargo de Director de la Sección Micología.

Obtuvo una beca de la Guggenheim Foundation que le permitió completar sus estudios con un título de Ms. Scs. en la Universidad de Michigan.

Se incorporó como docente a la UBA en 1958, donde ejerció como Profesor Titular con dedicación exclusiva, dictó los cursos regulares de Introducción a la Botánica, Morfología de Plantas Celulares y Micología. Se jubiló en 1988 y la Facultad lo nombra Profesor Consulto.

Investigador Superior del CONICET, miembro constante en sus comisiones. Académico de Número de la Academia Nacional de Ciencias Exactas y Naturales, que lo distinguió con el premio "C. M. Hicken" por su contribución al desarrollo de la micología en nuestro país. Presidente de la SAB por dos períodos, Director del Boletín y colaborador de su Comité Editorial, junto con otras revistas científicas de publicación periódica.

Organizó y dictó numerosos cursos de post-grado, en ocasiones invitó a prestigiosos investigadores especialistas extranjeros.

En los laboratorios de Micología que él dirigía, era constante la presencia de tesistas de Licenciatura y de Doctorandos, ya que tenía un carisma especial para captar alumnos, incluso de otras Universidades del país o de países vecinos.

La comunidad botánica le brindó un merecido homenaje en vida, al celebrar sus 70 años, dedicando un volumen completo de trabajos micológicos del Boletín de la SAB (28).

Publicó 115 trabajos en revistas periódicas y numerosos artículos de divulgación. Entre sus cinco libros tal vez su obra más preciada era la monografía mundial del género Tulostoma, ya que era conocida su predilección por los Gasteromycetes.

Aunque muchos de sus trabajos versan sobre la taxonomía de Basidiomycetes xilófagos, su amplitud de criterio y su amor por el reino de los hongos le permitió extender y diversificar sus 
temas de investigación. Esto fue acompañado y se ve reflejado en los numerosos discípulos que conforman el equipo de investigadores de la Facultad de Ciencias Exactas y Naturales (UBA).

Probablemente donde se sentía más cómodo era en su frondosa Biblioteca Micológica, donada al CONICET, donde se pueden consultar trabajos micológicos de la más diversa índole. Allí hacía uso de una certera y envidiable memoria y recordarba qué se había escrito previamente sobre prácticamente cualquier tema micológico.

También en el Herbario Micológico se movía con la misma agilidad y precisión para encontrar el ejemplar buscado o los más relacionados con lo que estuviera estudiando en ese momento. La abundancia y diversidad de materiales, principalmente de Argentina, además de otros lugares del mundo, convierten a este herbario en lugar de consulta obligado.

Esto indica claramente los dos pilares fundamentales que el Dr. Wright siempre remarcaba para cualquier estudio taxonómico: la bibliografía y el material de consulta.

Tuve la suerte de acompañarlo en su último viaje de colección al Parque Nacional Iguazú, junto con su inseparable esposa y compañera Quica y el Dr. Lechner. En la selva no dejaba de asombrar su vasto conocimiento, no solamente de los hongos, sino de la biología toda. Su memoria fotográfica deslumbraba ante cada hallazgo, aún de los ejemplares más pequeños, que no escapaban a sus ojos entrenados.

Aún con su salud delicada en los últimos años, nunca dejó de transmitir su entusiasmo por el trabajo que tuviera entre manos y por cualquier proyecto que considerara posible y que incluyera su más preciado sueño: el conocimiento de la micobiota del cono sur de América.

Siempre fue el Maestro para toda persona que quisiera dedicarse al estudio de los hongos. Lo consideramos un ejemplo de vida, tanto en la ciencia como en el aspecto humano. Para nosotros será una fuente irreemplazable.

Orlando F. Popoff 